Ионин В. А. ${ }^{1,2}$

${ }^{1}$ ФГБУ «Национальный медицинский исследовательский центр имени В. А. Алмазова» МинзАрава РФ, Санкт-Петербург, Россия

2 ФГБОУ ВО «Первый Санкт-Петербургский государственный меАицинский университет имени академика И. П. Павлова» Минздрава РФ, Санкт-Петербург, Россия

\title{
ПРОФИААКТИКА ТРОМБОЭМБОАИЧЕСКИХ
}

\section{ОСАОЖНЕНИЙ ПРИ ПРОВЕАЕНИИ КАРАИОВЕРСИИ И КАТЕТЕРНОЙ АБААЦИИ У ПАЦИЕНТОВ С ФИБРИ АЯЦИЕЙ ПРЕАСЕРАИЙ: ОБЗОР ОСНОВНЫХ РАНАОМИЗИРОВАННЫХ ИССАЕАОВАНИЙ}

В обзоре обсужАаются актуальность проблемы контроля синусового ритма у пациентов с фибримяяцией преАсерАий в реальной клинической практике, клинические особенности пациентов с Аанной аритмией и сопутствующей патологией, а также преАставлены современные рекомендации по профилактике тромбоэмболических осложнений и обзор результатов основных клинических исследований прямых пероральных антикоагулянтов. Поиск Аитературы и отбор клинических исследований был проведен за периоА с 2009 по 2020 гг. на сайтах Европейского и Российского обществ кардиологов, Всероссийского научного общества аритмологов, а также по онлайновым базам данных PubMed, EMBASE, eLibrary, Google Scholar с использованием ключевых слов: фибримяяция преАсердий, антикоагулянты, аблация, кардиоверсия, эффективность и безопасность, atrial fibrillation, anticoagulants, ablation, cardioversion, efficacy and safety.

Ключевые слова $\quad$ Фибримляция предсердий; кардиоверсия; катетерная аблация; антикоагулянты

Аля цитирования Ionin V.A. Prevention of thromboembolic complications during cardioversion and catheter ablation in patients with atrial fibrillation: review of key randomized trials. Kardiologiia. 2020;60(10):99-106. [Russian: Ионин В. А. Профилактика тромбоэмболических осложнений при проведении кардиоверсии и катетерной аблации у пациентов с фибримяяцией преАсерАий: обзор основных рандомизированных исследований. Кардиология. 2020;60(10):99-106]

Автор дıя переписки Ионин Ваяерий Александрович. E-mail: ionin.v.a@gmail.com

\section{Введение}

Фибримяяция предсердий (ФП) - одна из наиболее часто встречающихся суправентрикулярных аритмий, распространенность которой в попумяции составмяет $3 \%$ у миц старше 20 мет [1]. По результатам нашего когортного исследования, опубликованного ранее, в амбулаторной практике кардиологов г. Санкт-Петербурга встречаемость Аанной аритмии у пациентов, обратившихся на прием в периоА с 2014 по 2018 гг., составмяет 7,5\% и увекичилась за 5 мет в 1,3 раза, что безусловно отражает актуальность Аанной патологии в настоящее время [2]. В стратегии ведения больных с ФП в реальной клинической практике наиболее важными задачами являются контроль синусового ритма и частоты желудочковых сокращений, а также решение вопроса о профилактике системных тромбоэмболий в связи с тем, что наиболее важными осложнениями данной аритмии явмяются прогрессирующая хроническая сердечная недостаточность и нарушения мозгового кровообращения по карАиоэмболическому типу $[3,4]$. Решение вопроса о стратегии ведения пациентов с ФП согласно рекомендациям Европейского общества кардиологов (ESC, 2020), Аолжно приниматься в мультиАисциплинарной команде специалистов (врачи общей практики, кардиологи, специалисты по профилактике инсульта, аритмологи), что несомненно повышает эффективность терапии больных с ФП [5]. ОАнако в реальной практике организация такого поАхода к ме- чению пациентов с ФП возможна только в крупных многопрофильных специализированных центрах и стационарах, а в остальных ситуациях практикующему врачу приходится самостоятельно взаимодействовать с пациентом, провоАить стратификацию индивидуальных рисков и выстраивать эффективную стратегию ведения больного с ФП до провеАения кардиоверсии или аблации и посме выполненных процеАур. Выполнен поиск митературы и отбор клинических исследований за период с 2009 по 2020 гг. на сайтах Европейского и Российского обществ кардиологов, Всероссийского научного общества аритмологов, а также по онлайновым базам данных PubMed, EMBASE, eLibrary, Google Scholar с использованием ключевых слов: фибрилмяция предсердий, антикоагумянты, аблация, кардиоверсия, эффективность и безопасность, atrial fibrillation, anticoagulants, ablation, cardioversion, efficacy and safety. В этой публикации обобщены результаты завершенных кминических исслеАований по изучению эффективности и безопасности терапии прямыми пероральными антикоагулянтами (ПОАК) и преАставлены актуальные рекомендации аля принятия верного решения в клинической практике.

КарАиоверсия у пациентов с ФП: от рекоменАаций к реальной кАинической практике

По Аанным крупного европейского регистра больных с ФП (PREFER), в который вк^ючено 7243 пациента, 
у 50,7\% пациентов применялась стратегия контромя ритма, в том числе у 37,6\% пациентов проводилось восстановмение синусового ритма (кардиоверсия) [6]. Терапия, направменная на контроль синусового ритма, показана в первую очередь Аля уменьшения симптомов и повышения качества жизни у пациентов с ФП. Восстановление синусового ритма нереАко требуется пациентам с впервые зарегистрированной ФП или персистенцией Аанной аритмии. Согласно рекоменаациям ESC (2020), решение вопроса об экстренной электрической кардиоверсии возможно в случае острой нестабильности гемодинамики на фоне пароксизма ФП (класс рекомендаций I, уровень доказательности В). Во всех остальных случаях решение вопроса о проведении кардиоверсии Аолжно быть выполнено в плановом порядке с использованием меАикаментозной или электрической карАиоверсии в соответствии с клинической ситуацией и при согласии пациента. Возникновение пароксизма ФП и смена синусового ритма явцяются факторами, обусловмивающими изменения внутрипреАсерАной гемодинамики и изменение маминарных токов крови на турбулентные, которые явмяются причиной формирования тромботических масс в полости мевого предсердия и/или в ушке мевого предсердия ( $\Lambda П / У \Lambda П)$. Патогенетические механизмы тромбоэмболических осложнений (ТЭО) у пациентов, которым выполнялась кардиоверсия при ФП, изучены в размичных исследованиях еще до эры антикоагулянтной профилактики и, в частности, установлено, что риск ТЭО повышается до 5,3\% после кардиоверсии [7]. Представленные особенности течения пароксизма ФП требуют использования терапии антикоагукянтами Аля профилактики системных тромбоэмболий.

В соответствии с рекоменаациями ESC (2020) провеАение кардиоверсии без выполнения чреспищеводной эхокардиографии (ЧПЭхоКГ) (класс рекомендаций IIa, уровень Аоказательности В) возможно только в случае проАолжительности Аанной аритмии $<48$ часов. В то же время антикоагулянтная терапия гепарином или ПОАК Аолжна быть инициирована как можно раньше переА проведением кардиоверсии у пациентов с ФП или трепетанием преАсерАий (класс рекомендаций IІа, уровень доказательности В). Рекомендации Европейской ассоциации сердечного ритма (EHRA) рассматривают вариант ранней кардиоверсии у пациентов с Алительностью пароксизма $>48$ часов только при условии отсутствия тромботических масс

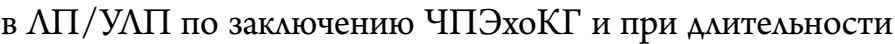
приема ПОАК от 2 Ао 4 часов Ао карАиоверсии, что безусмовно явмяется клинически значимым преимуществом использования ПОАК в сравнении с антагонистами витамина К (АВК), которые требуют Алительного приема Аля получения Аостаточного гипокоагумянтного эффекта [8]. Следует подчеркнуть, что при проведении кардиоверсии у пациентов с ФП необходима эффективная профилактика анти- коагулянтами не только при провеАении кардиоверсии, но и после восстановмения синусового ритма в течение как минимум 4 недель независимо от методики процедуры (класс рекомендаций I, уровень доказательности B), что подтвержАается резумьтатами ретроспективного анамиза Аатского национального регистра. При анализе медицинской документации 16274 пациентов с ФП, подвергшихся эмектрической кардиоверсии, было установлено, что у пациентов, не принимавших ОАК после восстановления синусового ритма в течение первых 30 Аней риск ТЭО был в 2 раза выше (относительный риск 2,25, 95\% Аоверительный интервах 1,43-3,53), чем у пациентов, принимающих ОАК [9]. Показания Аля Аальнейшего продолжения антикоагумянтной терапии в профилактике ТЭО опреАеляются согласно стратификации риска по шкале $\mathrm{CHA}_{2} \mathrm{DS}_{2} \mathrm{VASc}-2$ и более бамлов у мужчин и 3 и более баммов у женщин [5]. Во всех остальных случаях, когАа пароксизм ФП Алится $>48$ часов или Алительность его невозможно установить, в стратегии плановой кардиоверсии требуется преАваритемьная терапия антикоагулянтами в течение не менее 3 недемь (класс рекомендаций I, уровень доказательности В) при усмовии выполнения ЧПЭхоКГ. Отказ от проведения ЧПЭ хоКГ возможен только мишь в случае высокой комплаентности, когАа пациент Аает 100\% гарантию регумярного приема ПОАК, поАПисанную в меАицинской Аокументации. А^горитм поАготовки пациентов к плановой кардиоверсии преАставцен на рисунке 1 .

Выбор антикоагулянта при плановой кардиоверсии не менее важен, чем сроки выполнения этой процедуры, так как его Аействие Аолжно быть не только эффективным, но и безопасным. Важным предиктором успешности кардиоверсии и Алительности сохранения синусового ритма после этой процедуры является ремоделирование $\Lambda П$ и его Аилатация, поэтому Алительность антикоагулянтной подготовки пациента к кардиоверсии играет немаловажную роль, и чем Аольше персистирует ФП, тем выше вероятность значимого увеличения размеров $\Lambda П[10]$. При использовании АВК переА плановой кардиоверсией обязательным условием явмяется не только периоА антикоагумянтной терапии (не менее 3 недель), но и регулярный контромь Аостижения целевого значения межАународного нормализованного отношения (MHO) в Аиапазоне от 2 Ао 3 на протяжении всего периода. Следует подчеркнуть, что в случае регистрации нецелевого МНО рекомендовано продиить терапию АВК еще в течение 3 недель, и в реальной клинической практике такая ситуация не редкость, так как применение АВК ассоциировано с большим числом мекарственных и пищевых взаимодействий, что чаще всего увеличивает сроки поАГотовки пациента к плановой кардиоверсии [11]

Пациенты с ФП, которым выполнялась карАиоверсия, были включены во все многоцентровые Авойные слепые плацебо-контролируемые исследования ПОАК, зареги- 
Рисунок 1. Алгоритм ведения пациентов с фибримляцией предсердий до и после кардиоверсии, аАаптировано [8]

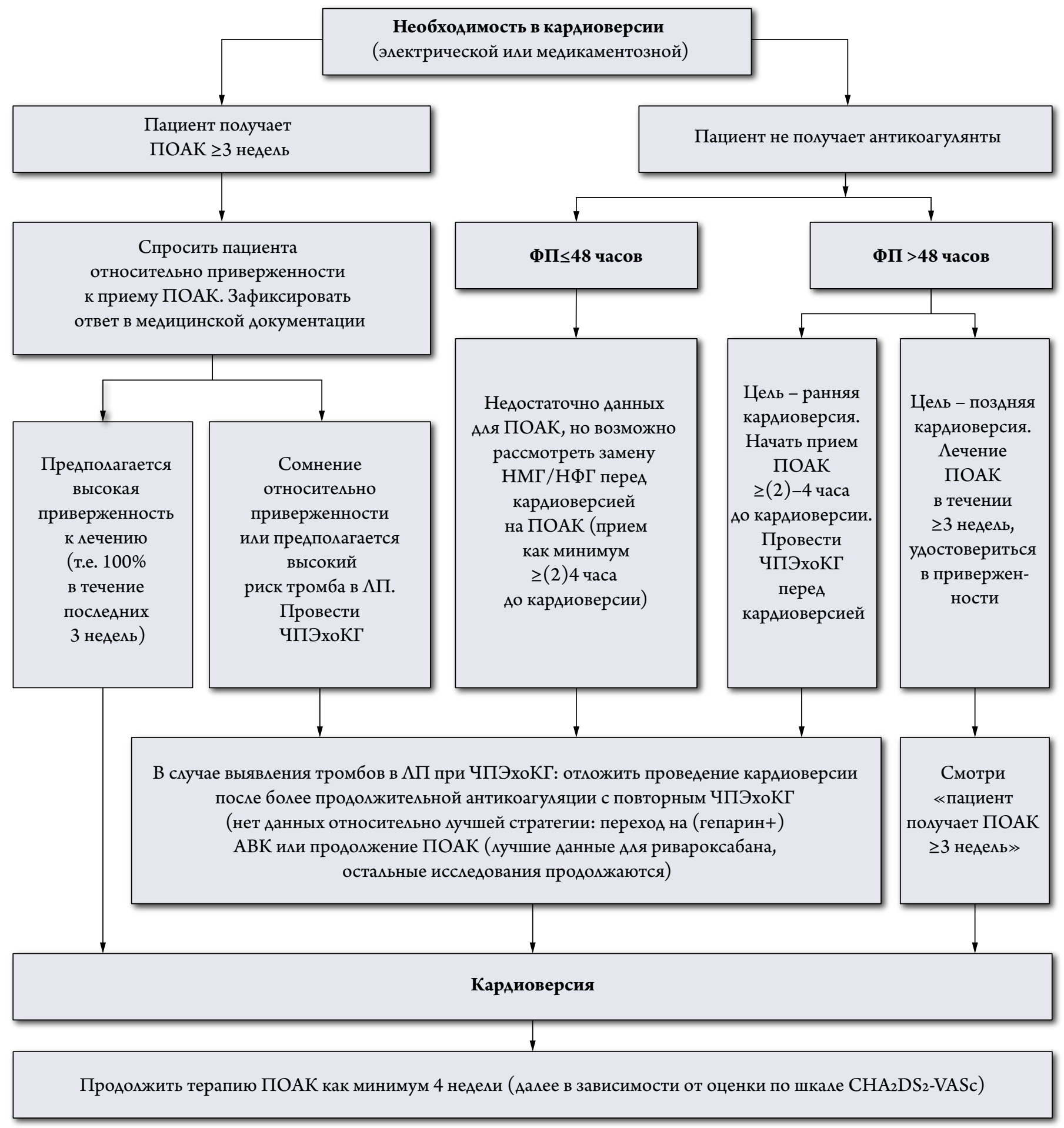

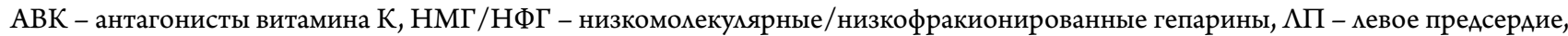
ПОАК - прямые орамьные антикоагулянты, ФП - фибримяция преАсердий, ЧПэхоКГ - чреспищеводная эхокарАиография. УАП - ушко мевого преАсерАия. Применение нагрузочной дозы апиксабана 10 мг (ими 5 мг) не зарегистрировано.

стрированных на территории России: дабигатран (RE-LY), ривароксабан (ROCKET-AF), апиксабан (ARISTOTLE). Так, по результатам post-hoc анализа исследования RE-LY, впервые ретроспективно была проанализирована когорта больных с ФП, получавших дабигатран в дозах 150 мг $(\mathrm{n}=672)$ и 110 мг $(\mathrm{n}=647)$ при выполнении кардиоверсии,

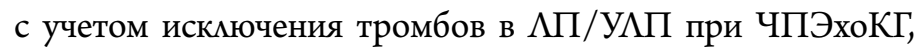

и частота ТЭО быма сопоставима с группой пациентов, покучавших варфарин [12]. В последующем в субанализе исслеАования ROCKET-AF у пациентов с ФП, которым проводимась аблация и кардиоверсия ( $\mathrm{n}=743)$, подтвердимась возможность не менее эффективного использования ривароксабана в сравнении с варфарином [13]. Протокол исслеАования ARISTOTLE также не искмючам пациентов с карди- 
оверсией, число которых составило 540 человек за все время исслеАования, не было выявлено повышения риска ТЭО на терапии апиксабаном в сравнении с варфарином [14]. Таким образом, терапия ПОАК Аля веАения пациентов, которым планируется кардиоверсия, обладала благоприятным профилем эффективности и безопасности в сравнении с АВК, но Аизайн всех 3 исслеАований не преАполагал Аетального изучения эффективности ПОАК при карАиоверсии, а приведенные результаты были получены при ретроспективном анализе.

Пациенты с ФП в реальной клинической практике нереАко имеют клинически значимые сопутствующие состояния (возраст, артериацьная гипертензия, хроническая серАечная недостаточность и сахарный Аиабет), которые увемичивают риск ТЭО. Распространенность факторов риска в когорте амбулаторных больных с ФП в практике кардиомога особенно высока у пациентов в возрасте 60 мет и старше, на Аолю которых приходится 82,3\% больных, и составмяет 90,1\% Аля артериальной гипертензии и 15,1\% Аля сахарного Аиабета, что значитемьно выше, чем у пациентов моложе 60 мет [2]. В связи с необходимостью Аетальной оценки рисков ТЭО у коморбиАных пациентов с ФП результаты первого проспективного открытого исследования $\mathrm{X}-\mathrm{VeRT}$, в котором проводияось сравнение ривароксабана и АВК прицемьно у больных с кардиоверсией, стали настоящим фунАаментом в понимании показателей эффективности и безопасности использования данного препарата у пациентов с ФП. В исследование X-VeRT было включено 1504 пациента с неклапанной ФП, которым была показана плановая кардиоверсия. Следует подчеркнуть, что средний возраст пациентов составия 64,9 года, а Аоля пациентов с артериальной гипертензией - 65\%, сахарным диабетом - 20,3\%, a 55,9\% были с персистирующей формой Аанной аритмии, что свидетельствует о включении в исследование пациентов, наиболее приближенных к реальной клинической практике. В результате проспективного наблюдения установцено, что в группе пациентов, принимавших ривароксабан, отмечалась меньшая частота развития не только инсульта, но и всех серАечно-сосудистых событий, вкАючивших инсульт, системную эмболию, транзиторную ишемическую атаку и сердечно-сосудистую смерть (0,51\% против 1,02\% в группе с $\mathrm{ABK})$, а также благоприятный профиль безопасности, характеризующийся снижением частоты кровотечений $(0,61 \%$ против $0,8 \%$ в группе АВК). Важным результатом исследования X-VeRT Аля реальной клинической практики стало сокращение медианы времени от рандомизации Ао кардиоверсии у пациентов, получавших ривароксабан (22 Аня), чем у пациентов на терапии АВК (30 Аней), что бымо обусловлено необходимостью титрации дозы варфарина Аля Аостижения цемевых значений МНО [13].

В 2018 г. опубликованы результаты исследования EMANATE, в котором изучены эффективность и безопас- ность апиксабана в сравнении с АВК у пациентов с ФП и карАиоверсией $(\mathrm{n}=1038)$. В первую очередь следует подчеркнуть, что, согласно Аизайну исследования, пациентам с ФП проводилась кардиоверсия только после приема 5 стандартных Аоз апиксабана (5 мг или 2,5 мг в соответствии с инструкцией по снижению дозы) или по усмотрению исслеАователя в ускоренном протоколе использовацась нагрузочная доза 10 мг разово за 2 часа до процедуры восстановление ритма, которая в Аальнейшем снижалась и пациенты получами 5 мг или 2,5 мг Ава раза в Аень в периоА проспективного наблюАения, что нужно учитывать при использовании Аанного препарата в реальной клинической практике. По результатам исследования, продемонстрированы не меньшая эффективность апиксабана, чем у варфарина (0\% против 0,8\% в группе с АВК), и благоприятный профиль в отношении риска больших кровотечений (0,43\% против 0,83\% в группе АВК) [15].

В клинической практике также следует учитывать, что в исслеАование EMANATE включались пациенты с Алительностью пароксизма ФП не более 48 часов, а в исслеАовании $\mathrm{X}-\mathrm{VeRT}$ Аополнительно изучена стратегия ранней кардиоверсии с приемом ривароксабана от 2 Ао 4 часов Ао процеАуры у пациентов с Алительностью пароксизма ФП более 48 часов и отсутствием признаков тромботических масс

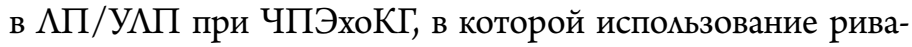
роксабана характеризовалось таким же профилем эффективности и безопасности, как и в стандартной схеме антикоагулянтной поАготовки в течение 3 недемь при плановой кардиоверсии. Этот факт в 2018 г. позволик внести в ацгоритм плановой кардиоверсии возможность ранней кардиоверсии у пациентов с более затяжными пароксизмом ФП (более 48 часов), что, по сути, продемонстрировано в проспективном исследовании только у ривароксабана.

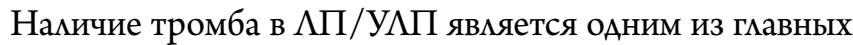
абсолютных противопоказаний Аля проведения кардиоверсии у больных с ФП, однако у этих пациентов антикоагумянтная профимактика ТЭО еще более актуамьна. По итогам наблюдательных и проспективных исследований, не бымо установлено размичий в частоте образования тромбов в $\Lambda$ ПУАП у пациентов, получавших АВК и ПОАК [12-14] В настоящее время нет жестких кминических Аанных о наимучшей стратегии мечения тромба $\Lambda П / У \Lambda П$ на фоне терапии мюбым антикоагумянтом, а стандартной терапией, рекоменАованной в Аанной клинической ситуации, явмяется терапия АВК с тщательным контролем и мониторингом $\mathrm{MHO}$ Ао исчезновения тромботических масс. ОАнако недавнее проспективное исследование X-TRA показало, что использование ривароксабана в стандартной Аозе (20 мг в Аень) в течение 6 недель приводило к исчезновению тромботических масс у 41,5\% (22/53) пациентов, а к исчезновению и уменьшению в объеме тромботических масс - у 60,4\% (32/53). Результаты протокола X-TRA при непрямом срав- 


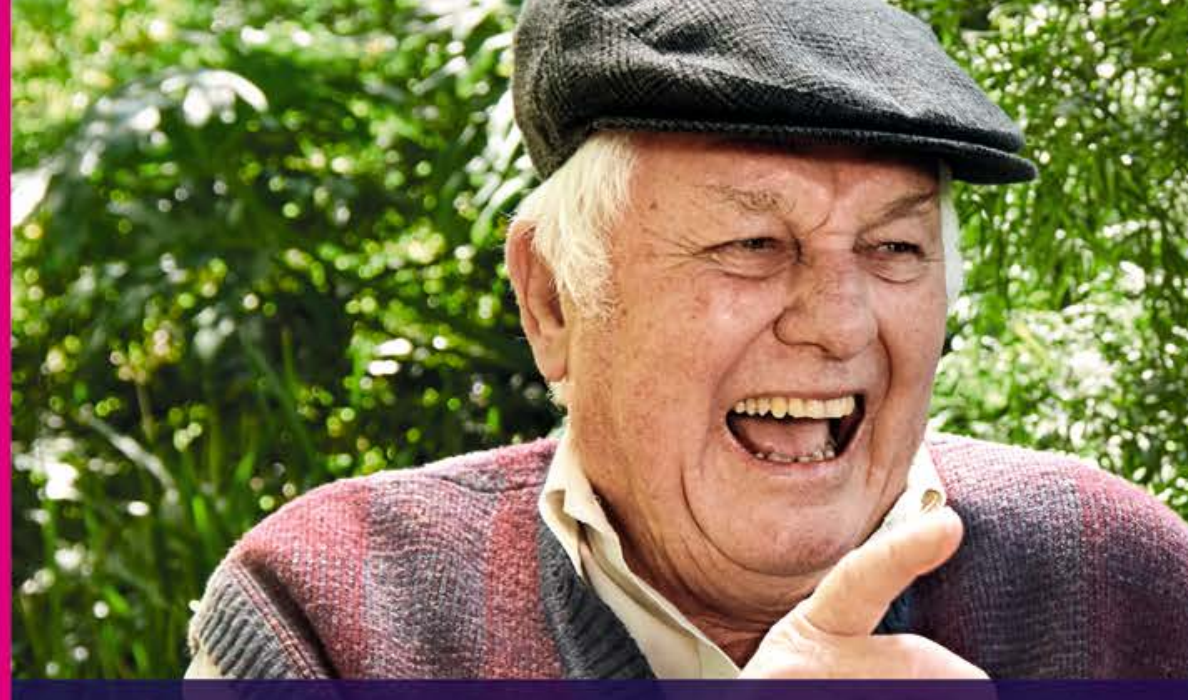

А что Аля Вас значит надежно и бережно заботиться о близких?

Даже у пожилых пациентов с ФП Ксарелто снижал риск инсульта и жизнеугрожающих кровотечений в сравнении с варфарином',*

Ксарелто способствовал лучшему сохранению функции почек у пациентов с ФП в сравнении с варфарином ${ }^{2, * *}$

У широкого круга пациентов, в том числе пожилых с ФП, Ксарелто снижал риски как инсульта, так и ИМ/OKС ${ }^{3, \#}$

Однократный режим дозирования и календарная упаковка Ксарелто могут помочь пожилым

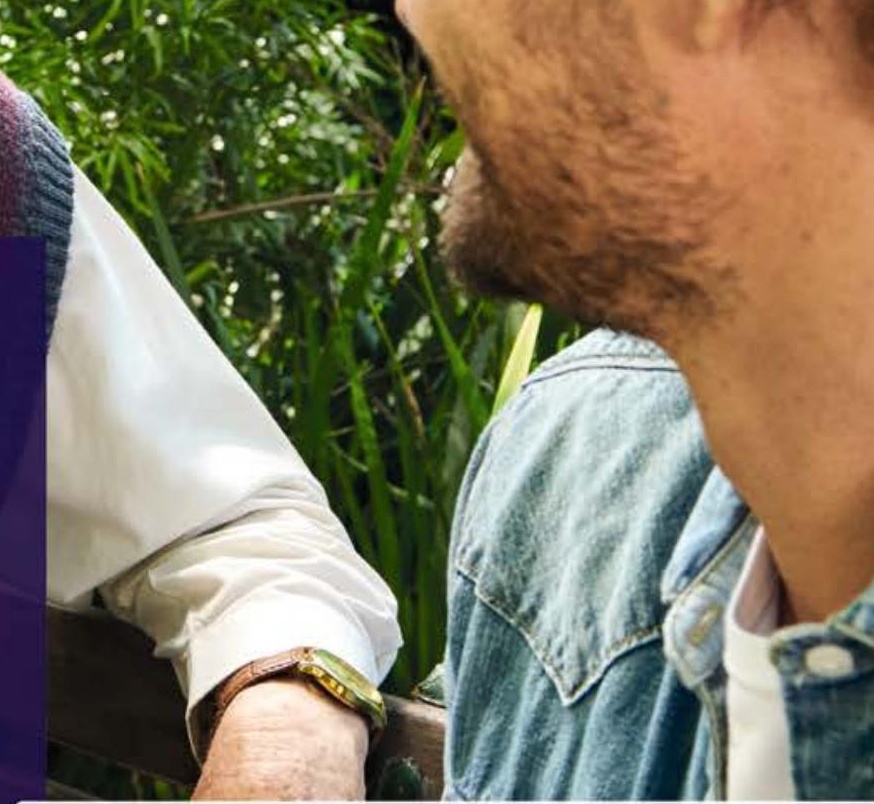
пациентам соблюдать ваши рекомендации ${ }^{4-6}$

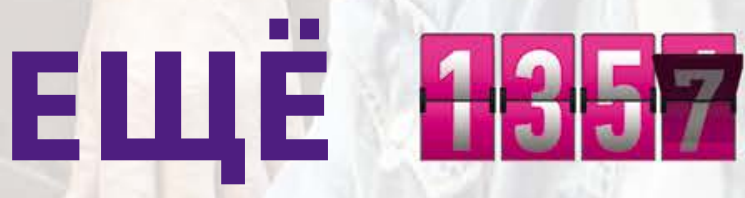

ДЕДУШКИНЫХ ШУТОК
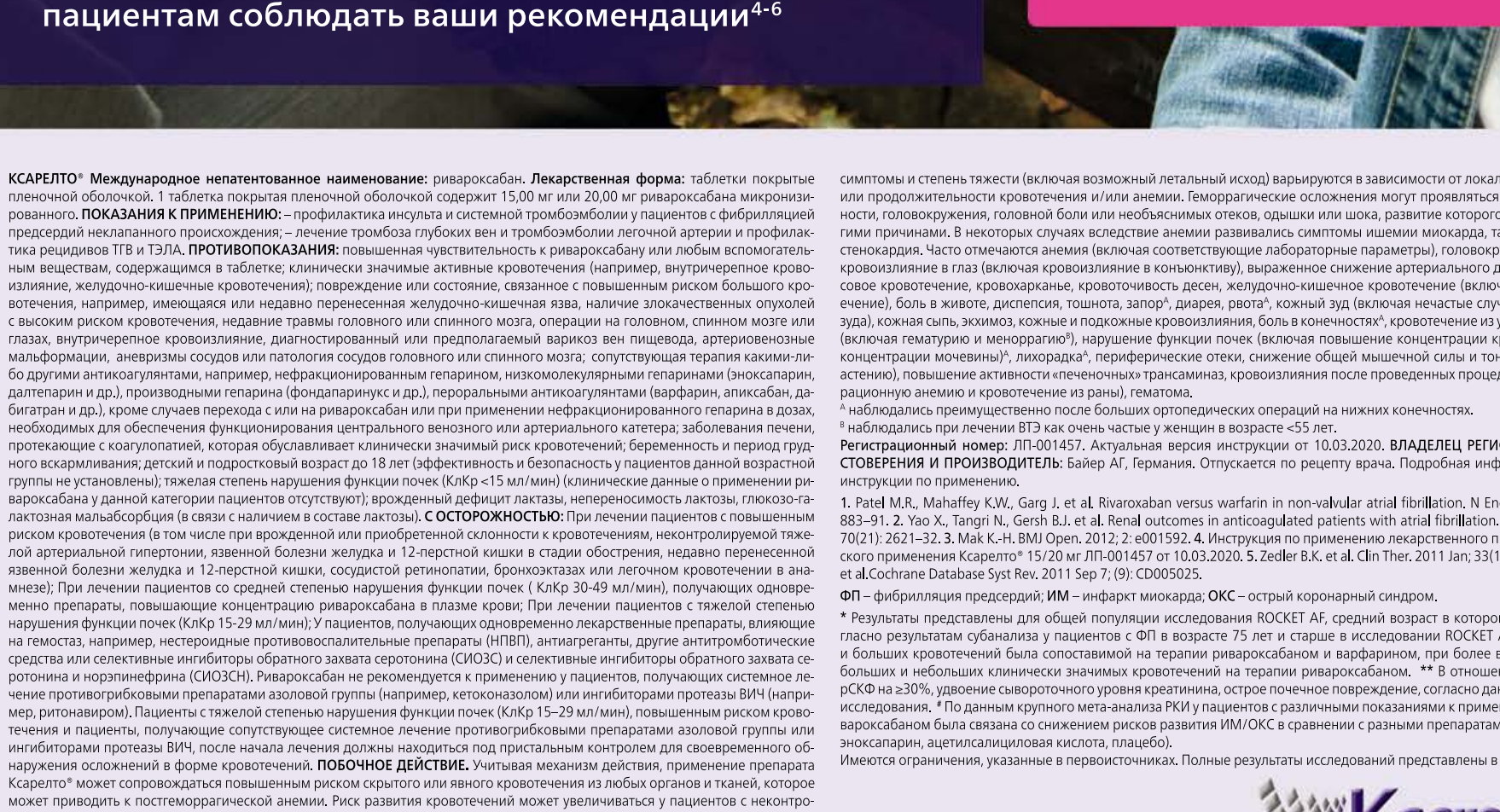
нении были сопоставимы с результатами ретроспективного исследования регистра CLOT-AF, в котором исчезнове-

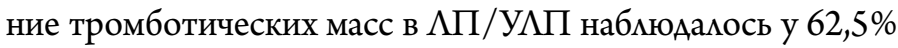
(60/96) пациентов, покучавших гепарин/варфарин [16].

В исследовании EMANATE не планировалось изучение влияния апиксабана на тромбы в $\Lambda П / У \Lambda П$, тем не менее такие пациенты были и при визуализации с помощью ЧПЭхоКГ и компьютерной томографии. Частота исчезновения тромба была сопоставимой у пациентов на терапии апиксабаном $(52 \%, 12 / 23)$ и АВК $(56 \%, 10 / 18)$, оАнако в Аанном исследовании не бымо проспективного наблюдения за пациентами с тромбами в $\Lambda П / У \Lambda П$ и выборка больных была малочисленной [15]. Исследование терапии Аа-

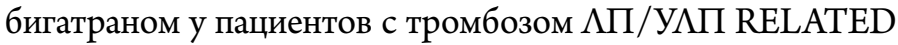
$\mathrm{AF}$ (NCT02256683) в настоящее время еще продолжается и результаты не представлены. В совокупности эти выводы указывают на то, что использование ПОАК Амя терапии

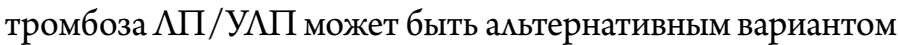
(кучшие данные в настоящее время продемонстрированы Амя ривароксабана), в особенности у пациентов с непереносимостью АВК или в том случае, если нет возможности Аостигнуть адекватного контроля МНО [8].

Таким образом, использование ПОАК Амя профилактики ТЭО у пациентов, которым планируется кардиоверсия, не уступает по показатемям эффективности и безопасности ABК, а в реальной клинической практике Аает преимущество по срокам выполнения Аанной процедуры, но, с учетом разных сроков и сопутствующей патологии, требует персонализированного подхода в выборе антикоагумянта.

\section{Катетерная аблация у пациентов}

с ФП: от рекоменАаций к реальной кАинической практике

С 2020 г., согласно рекомендациям ESC по мечению ФП, определена стратегия мечения пациентов с пароксизмальной и персистирующей формами данной аритмии, которая подразумевает восстановление и подАержание синусового ритма или контроль частоты серАечных сокращений. Аанная стратегия может осуществляться с помощью применения антиаритмической терапии (ААТ) мибо интервенционного мечения ФП. ОАнако назначение антиаритмических препаратов I класса возможно только больным, не имеющим значимых структурных изменений миокарда [5]. Применение соталола, как правило, недостаточно эффективно и показано, прежде всего, пациентам с ишемической болезнью серАца [17]. Алительный прием амиодарона часто сопровождается развитием осложнений: амиодарониндуцированной дисфункции щитовидной железы, амиоАарон-индуцированного фиброза мегких [18]. Также существенный вклад в ограничение медикаментозной терапии вносит проаритмический эффект, которым обладают все антиаритмические препараты [19]. В связи с этим паци- ентам с отсутствием эффекта от ААТ и наличием симптомной ФП, оцениваемой по шкале EHRA, рекомендовано выполнение катетерной аблации Аля подАержания синусового ритма (класс рекомендаций I, уровень доказательности А) [5]. Также выбор в пользу интервенционных методов мечения может основываться на непосредственном выборе пациента.

Многочисленными рандомизированными кминическими исслеАованиями Аоказано, что радиочастотная изоляция устьев мегочных вен явмяется более эффективным методом контроля ритма у пациентов с ФП, чем ААТ. Такие исследования, как CACAF, APAF, A4 и CABANA, свидетельствуют о более высокой эффективности радиочастотной изоляции устьев мегочных вен с целью восстановления синусового ритма и его подАержания, чем использование кекарственной терапии. После интервенционного мечения «свобода от аритмии» наблюАается у 59-89\% (в среднем у 70\%) пациентов без использования антиаритмических препаратов [20]. В реальной клинической практике в когорте пациентов г. Санкт-Петербурга на амбулаторном приеме кардиолога у 5,1\% пациентов с ФП выполнялась катетерная аблация в анамнезе [2].

Процедура катетерной аблации относится к категории малоинвазивных интервенционных вмешательств, однако ее проведение в ряде случаев сопряжено с риском осложнений. В целом частота осложнений процеАуры катетерной аблации не высокая - Ао 4,5\% по Аанным европейских регистров, однако среАи жизнеугрожающих: тампонада серАца $(1,31 \%)$, феморальная псевдоаневризма $(0,93 \%)$, артериовенозная фистука $(0,54 \%)$, поэтому риск кровотечений у пациентов с ФП, подвергшихся катетерной аблации, высокий [5]. С Аругой стороны, процедура катетерной аблации вне зависимости от методики (криоаблация, радиочастотная аблация) в связи с воздействием на эндокарА ассоциирована с риском тромбообразования и инсульта (1\%) [21, 22]. Согласно рекомендациям ESC (2020), при планировании катетерной аблации ФП продолжение терапии ОАК: АВК (класс рекомендаций ІІа, уровень доказательности В) ими ПОАК (класс рекомендаций ІІа, уровень доказательности С), следует рассмотреть Аля поддержания эффективной гипокоагумяции и продолжать в течение не менее 8 недель после процедуры (класс рекомендаций IІа, уровень доказательности В). У пациентов с высоким риском инсульта $\left(\mathrm{CHA}_{2} \mathrm{DS}_{2} \mathrm{VASc}-2\right.$ и более баммов у мужчин и 3 и более балмов у женщин) после успешной катетерной или хирургической аблации ФП следует продолжать прием антикоагулянтов (класс рекомендаций ІІа, уровень доказательности С). При использовании АВК рекомендован целевой уровень MHO от 2 Ао 2,5 Аля уменьшения риска кминически значимых кровотечений [5]. Особенности фармакокинетики ПОАК, позволяющие в большей степени управмять антикоагулянтным эффектом, преАставмяются как имеющие бомее 
высокие показатели безопасности в реальной клинической практике, к тому же в настоящее время завершены исслеАования со всеми ПОАК у пациентов с ФП и катетерной аблацией.

Впервые профиль безопасности ПОАК в Аанной когорте больных в 2015 г. быи продемонстрирован в многоцентровом рандомизированном исследовании с активным контролем и заслеплением конечных точек VENTURE AF Аля ривароксабана в стандартной дозе 20 мг в Аень. При проведении процедуры аблации на фоне непрерывной терапии ривароксабаном были показаны сопоставимые результаты по показатемям эффективности и безопасности в сравнении с непрерывной терапией варфарином. Отсутствие нежелательных событий (ишемический инсульт, сердечно-сосудистая смерть и большие кровотечения) в группе пациентов, получавших ривароксабан, не позволило установить статистически значимых размичий, оАнако следует отметить, что осложнения в группе пациентов, получавших варфарин, были тем не менее зарегистрированы. Серьезные нежелательные явления, послужившие причиной отмены терапии, значимо реже встречались в группе ривароксабана, чем у больных на терапии АВК (0,8\% и 2,5\%) [23]. Таким образом, терапия ривароксабаном у больных с ФП преАставляется Аостойной альтернативой использованию АВК, в том числе у пациентов, которым планируется не только карАиоверсия, но и катетерная аблация, что подтверждается и в реальной клинической практике. В крупнейшем мета-анамизе, включавшем 15 исследований и 8872 пациента с ФП, подвергшихся катетерной аблации и кардиоверсии, риск инсульта у пациентов на терапии ривароксабаном быи ниже, чем у пациентов, принимавших $\mathrm{ABK}(\mathrm{OP}=0,33,95 \%$ АИ: 0,11-0,95, p=0,04), а риск больших и малых кровотечений быи сопоставим в обеих группах $(\mathrm{OP}=0,92,95 \%$ АИ: 0,62$1,36, \mathrm{p}=0,68)[24]$.

В настоящее время завершены еще 2 крупных многоцентровых рандомизированных исслеАования, посвященных оценке безопасности и эффективности ПОАК: Аабигатран (RE-CIRCUIT) [25] и апиксабан (AFAXA-AFNET 5) [26]. Оба исследования также продемонстрировали возможность использования этих препаратов с сопоставимым профилем эффективности в сравнении с АВК. Использование апиксабана по итогам исследования AFAXA-AFNET 5 облаАало схожим профилем эффективности в сравнении с АВК по комбинированной конечной точке (смерть от всех причин, инсульт и большое кровотечение) - 22 (6,9\%) против 23 (7,3\%). ОАнако при отсутствии инсультов и транзиторных ишемических атак у пациентов в группе АВК, у 2 (0,6\%) пациентов, получавших апиксабан, были зарегистрированы эти нежелательные события. В клинической практике при использовании апиксабана также следует учитывать, что в протоколе исследования AFAXA-AFNET 5 изучены 2 режима антикоагумянтной поАготовки: первый - апиксабан в дозе 5 мг 2 раза в день в течение не менее 30 Аней Ао провеАения аблации и второй - ускоренный протокол с приемом как минимум 2-х стандартных Аоз препарата и искмючении тромботических масс в $\Lambda$ ПУ $\Lambda$ переА процеАурой аблации.

B исследовании RE-CIRCUIT у пациентов, получавших Аабигатран, кровотечения наблюдались реже, чем в группе АВК - 5 (1,6\%) против 22 (6,9\%), ОАнако следует поАчеркнуть, что в исслеАовании RE-CIRCUIT была изучена только Аозировка Аабигатрана 150 мг, что следует учитывать в практике, а число нежелательных явлений, потребовавших прерывание терапии этим препаратом, было выше, чем в группе АВК - 19 (5,6\%) против 8 (2,4\%), в большей степени обусловленные Аиспепсическими явлениями со стороны жекудочно-кишечного тракта [25]. В реальной практике пациенты с ФП нереАко имеют сопутствующую патологию: ишемическую болезнь серАца, хроническую серАечную неАостаточность, сахарный Аиабет, часто осложненный нарушением функции почек, требующих от ПОАК не только эффективной профилактики ТЭО, но и благоприятного профимя в отношении сопутствующих заболеваний, что соответствует резумьтатам исслеАований ROCKET-AF, X-VeRT, VENTURE по использованию ривароксабана у пациентов с ФП, а возможность однократного приема ривароксабана в течение Аня позволит повысить приверженность пациентов такой терапии и Алительность защиты от системных тромбоэмболий. Приверженность терапии ПОАК играет немаловажную роль, так как после процедуры аблации в течение как минимум 8 недель, а в случае высокого риска ТЭО в течение всей жизни, показана непрерывная терапия антикоагулянтами. Хорошо известно, что оАнократный прием кардиологических препаратов повышает приверженность терапии [27], а режим однократного приема антикоагумянта возможен только Аля ривароксабана из зарегистрированных препаратов в Российской ФеАерации.

\section{Заключение}

В целом терапия ПОАК у пациентов с ФП, которым пианируется проведение катетерной аблации, в настоящее время по выводам клинических исследований всех препаратов обладает сопоставимым профилем эффективности в сравнении с АВК, а в реальной клинической практике и более высокими показатемями безопасности. Выбор антикоагумянта Ао проведения процеАур Аолжен быть слелан в кажАом конкретном случае индивидуально, так как показатели эффективности ПОАК важны не только после процеАуры аблации, но и на протяжении всей жизни пациента с высоким риском ТЭО и нереАко с коморбидными состояниями.

Публикация подготовлена

при поддержке компании АО БАЙЕР.

PP-XAR-RU-0467-1.

Статья поступима 27.06.2020 
1. Staerk L, Sherer JA, Ko D, Benjamin EJ, Helm RH. Atrial Fibrillation: Epidemiology, Pathophysiology, and Clinical Outcomes. Circulation Research. 2017;120 (9):1501-17. DOI: 10.1161/CIRCRESAHA.117.309732

2. Ionin V.A., Barashkova E. I., Filatova A. G., Baranova E. I., Shlyakhto E.V. Atrial fibrillation in St Petersburg cohort: frequency, risk factors, antiarrhythmic therapy and thromboembolism prevention. Arterial Hypertension. 2020;26 (2):192-201. [Russian: Ионин В.А., Барашкова Е.И., Филатова А.Г., Баранова Е.И., Шияхто Е.В. Фибримяяция преАсерАий в когорте амбулаторных пациентов Санкт-Петербурга: встречаемость, факторы риска, антиаритмическая терапия и профикактика тромбоэмболических осложнений. Артериальная гипертензия. 2020;26 (2):192-201]. DOI: 10.18705/1607-419X-2020-26-2-192-201

3. Chugh SS, Havmoeller R, Narayanan K, Singh D, Rienstra M, Benjamin EJ et al. Worldwide epidemiology of atrial fibrillation: a Global Burden of Disease 2010 Study. Circulation. 2014;129 (8):837-47. DOI: 10.1161/CIRCULATIONAHA.113.005119

4. Sulimov V.A., Golitsin S. P., Panchenko E.P., Popov S. V., Revishvili A.Sh., Shubik Yu. V. et al. Diagnosis and treatment of atrial fibrillation. Recommendations of RSC, RSSA and ACVS. Russian Journal of Cardiology. 2013;18 (4 S3):1-100. [Russian: Сулимов В.А., Голицын С.П., Панченко Е. П., Попов С. В., Ревишвили А.Ш., Шубик Ю. В. и Ар. Аиагностика и мечение фибримяяции преАсерАий. РекоменАации РКО, ВНОА и ААСХ. Российский карАиологический журнал. 2013;18 (4 S3):1-100]

5. Hindricks G, Potpara T, Dagres N, Arbelo E, Bax JJ, Blomström-Lundqvist $C$ et al. 2020 ESC Guidelines for the diagnosis and management of atrial fibrillation developed in collaboration with the European Association of Cardio-Thoracic Surgery (EACTS). European Heart Journal. 2020; ehaa612. [Epub ahead of print]. DOI: 10.1093/eurheartj/ehaa612

6. Kirchhof P, Ammentorp B, Darius H, De Caterina R, Le Heuzey J-Y, Schilling RJ et al. Management of atrial fibrillation in seven European countries after the publication of the 2010 ESC Guidelines on atrial fibrillation: primary results of the PREvention oF thromboemolic events European Registry in Atrial Fibrillation (PREFER in AF). EP Europace. 2014;16 (1):6-14. DOI: 10.1093/europace/eut263

7. Bjerkelund CJ, Orning OM. The efficacy of anticoagulant therapy in preventing embolism related to $D$. C. electrical conversion of atrial fibrillation. The American Journal of Cardiology. 1969;23 (2):208-16. DOI: 10.1016/0002-9149 (69) 90068-X

8. Steffel J, Verhamme P, Potpara TS, Albaladejo P, Antz M, Desteghe L et al. The 2018 European Heart Rhythm Association Practical Guide on the use of non-vitamin $\mathrm{K}$ antagonist oral anticoagulants in patients with atrial fibrillation. European Heart Journal. 2018;39 (16):1330-93. DOI: 10.1093/eurheartj/ehy136

9. Hansen ML, Jepsen RMHG, Olesen JB, Ruwald MH, Karasoy D, Gislason $\mathrm{GH}$ et al. Thromboembolic risk in 16274 atrial fibrillation patients undergoing direct current cardioversion with and without oral anticoagulant therapy. EP Europace. 2015; 17 (1):18-23. DOI: 10.1093/europace/euu189

10. den Uijl DW, Bax JJ. Left atrial size as a predictor of successful radiofrequency catheter ablation for atrial fibrillation. Europace. 2009; 11 (10):1255-6. DOI: 10.1093 /europace/eup285

11. Drugs.com. Warfarin Drug Interactions. [Internet] Available at: https:// www.drugs.com/drug-interactions/warfarin.html

12. Nagarakanti R, Ezekowitz MD, Oldgren J, Yang S, Chernick M, Aikens TH et al. Dabigatran Versus Warfarin in Patients With Atrial Fibrillation: An Analysis of Patients Undergoing Cardioversion. Circulation. 2011;123 (2):131-6. DOI: 10.1161/CIRCULATIONAHA.110.977546

13. Cappato R, Ezekowitz MD, Klein AL, Camm AJ, Ma C-S, Le Heuzey J-Y et al. Rivaroxaban vs. vitamin $\mathrm{K}$ antagonists for cardioversion in atri- al fibrillation. European Heart Journal. 2014;35 (47):3346-55. DOI: 10.1093/eurheartj/ehu367

14. Flaker G, Lopes RD, Al-Khatib SM, Hermosillo AG, Hohnloser SH, Tinga $B$ et al. Efficacy and Safety of Apixaban in Patients After Cardioversion for Atrial Fibrillation: Insights from the ARISTOTLE trial (Apixaban for Reduction in Stroke and Other Thromboembolic Events in Atrial Fibrillation). Journal of the American College of Cardiology. 2014;63 (11):1082-7. DOI: $10.1016 /$ j.jacc.2013.09.062

15. Ezekowitz MD, Pollack CV, Sanders P, Halperin JL, Spahr J, Cater N et al. Apixaban compared with parenteral heparin and/or vitamin K antagonist in patients with nonvalvular atrial fibrillation undergoing cardioversion: Rationale and design of the EMANATE trial. American Heart Journal. 2016;179:59-68. DOI: 10.1016/j.ahj.2016.06.008

16. Lip GYH, Hammerstingl C, Marin F, Cappato R, Meng IL, Kirsch B et al. Left atrial thrombus resolution in atrial fibrillation or flutter: Results of a prospective study with rivaroxaban (X-TRA) and a retrospective observational registry providing baseline data (CLOT-AF). American Heart Journal. 2016;178:126-34. DOI: 10.1016/j.ahj.2016.05.007

17. Milan DJ, Saul JP, Somberg JC, Molnar J. Efficacy of Intravenous and Oral Sotalol in Pharmacologic Conversion of Atrial Fibrillation: A Systematic Review and Meta-Analysis. Cardiology. 2017;136 (1):52-60. DOI: $10.1159 / 000447237$

18. Waks JW, Zimetbaum P. Antiarrhythmic Drug Therapy for Rhythm Control in Atrial Fibrillation. Journal of Cardiovascular Pharmacology and Therapeutics. 2017;22 (1):3-19. DOI: 10.1177/1074248416651722

19. Frommeyer G, Eckardt L. Drug-induced proarrhythmia: risk factors and electrophysiological mechanisms. Nature Reviews. Cardiology. 2016;13 (1):36-47. DOI: $10.1038 /$ nrcardio.2015.110

20. Packer DL, Mark DB, Robb RA, Monahan KH, Bahnson TD, Moretz K et al. Catheter Ablation versus Antiarrhythmic Drug Therapy for Atrial Fibrillation (CABANA) Trial: Study Rationale and Design. American Heart Journal. 2018;199:192-9. DOI: 10.1016/j.ahj.2018.02.015

21. Cappato R, Calkins H, Chen S-A, Davies W, Iesaka Y, Kalman J et al. Updated Worldwide Survey on the Methods, Efficacy, and Safety of Catheter Ablation for Human Atrial Fibrillation. Circulation: Arrhythmia and Electrophysiology. 2010;3 (1):32-8. DOI: 10.1161/CIRCEP.109.859116

22. Haeusler KG, Kirchhof P, Endres M. Left Atrial Catheter Ablation and Ischemic Stroke. Stroke. 2012;43 (1):265-70. DOI: 10.1161/STROKEAHA.111.627067

23. Cappato R, Marchlinski FE, Hohnloser SH, Naccarelli GV, Xiang J, Wilber DJ et al. Uninterrupted rivaroxaban vs. uninterrupted vitamin $\mathrm{K}$ antagonists for catheter ablation in non-valvular atrial fibrillation. European Heart Journal. 2015;36 (28):1805-11. DOI: 10.1093/eurheartj/ehv177

24. Nairooz R, Sardar P, Pino M, Aronow WS, Sewani A, Mukherjee D et al. Meta-analysis of risk of stroke and thrombo-embolism with rivaroxaban versus vitamin $\mathrm{K}$ antagonists in ablation and cardioversion of atrial fibrillation. International Journal of Cardiology. 2015;187:345-53. DOI: 10.1016/j.ijcard.2015.03.323

25. Calkins H, Willems S, Gerstenfeld EP, Verma A, Schilling R, Hohnloser SH et al. Uninterrupted Dabigatran versus Warfarin for Ablation in Atrial Fibrillation. New England Journal of Medicine. 2017;376 (17):1627-36. DOI: 10.1056/NEJMoa1701005

26. Di Biase L, Callans D, Hæusler KG, Hindricks G, Al-Khalidi H, Mont L et al. Rationale and design of AXAFA-AFNET 5: an investigator-initiated, randomized, open, blinded outcome assessment, multi-centre trial to comparing continuous apixaban to vitamin $\mathrm{K}$ antagonists in patients undergoing atrial fibrillation catheter ablation. EP Europace. 2017;19 (1):132-8. DOI: 10.1093/europace/euw368

27. Coleman CI, Roberts MS, Sobieraj DM, Lee S, Alam T, Kaur R. Effect of dosing frequency on chronic cardiovascular disease medication adherence. Current Medical Research and Opinion. 2012;28 (5):669-80. DOI: 10.1185/03007995.2012.677419 